\title{
Comparison of Traditional and Digital Reference Questions and Responses at the National Library and Archives of I.R. of Iran (NLAI)
}

\section{Sedigheh Shakeri, Saeedeh Akbaridaryan, and Farnaz Mohammadi}

\section{Sedigheh Shakeri (s-shakeri@nlai. ir) is Virtual Reference Librarian, National Library and Archives of Islamic Republic of Iran; Saeedeh Akbaridaryan (sakbaridaryan@ gmail.com) is Manager of Digital Resources Administration in National Library and Archives of Islamic Republic of Iran; and Farnaz Mohammadi (f-mohammadi@NLAI. ir) is Supervisor of Virtual Reference Section in National Library and Archives of Islamic Republic of Iran}

Reference \& User Services Quarterly, vol. 52, no. 2, pp. 136-44 ๑) 2012 American Library Association. All rights reserved.

Permission granted to reproduce for nonprofit, educational use.
The researchers seek to assess the characteristics of users of reference services and their information needs to know how to qualitatively and quantitatively improve these types of services at the NLAI. Findings of this study indicated that the most frequently asked questions at the reference desks of the NLAI were ready reference questions (33.55 percent) and the least common questions were research-based (17.34 percent). Females (65.53 percent) mostly used traditional reference service but males (54.55 percent) used virtual reference service more. Also analysis showed that the most common and the least common question types at the traditional reference desk were ready reference (42.42 percent) and research questions (6.89 percent) respectively; and those asked through virtual reference were research (32.28 percent) and directory (20.08 percent) questions respectively. Most of the questions asked by clients of both traditional and virtual reference services could be classified in computer science, information, and general works (000) (30.58 percent) while the fewest questions were clustered in philosophy and psychology (100) (1.18 percent).

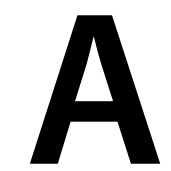
lthough different models of reference services have been studied exhaustively in libraries, there has been no empirical examination comparing both models of reference services (traditional and virtual) at a national library. This study analyzes all traditional and virtual reference queries within one month from December 2, 2010, up to January 2, 2011, comprising 258 virtual reference questions and 354 traditional reference questions.

The National Library and Archives of the Islamic Republic of Iran (NLAI) is an educational, scholarly, research, and service-providing institution that operates under the supervision of a Board of Trustees headed by the President of Iran.

The official establishment of the National Library goes back to 1937 , and its constitution was approved by the National Consultative Assembly in 1991. To ensure optimum performance several institutions were merged in the National Library, including the former Pahlavi Library (1979), Tehran Book Processing Center (1983), Institute of Cultural Documents of the Islamic Revolution (1999), and National Archives of Iran (2002), creating the present organization. The NLAI consists of four divisions: 1. National Archives, 2. National Library, 3. Research, Planning, and Information Technology, and 4. Support Operations. These four divisions operate in two separate buildings: National Library building, and National Archives building. 
The NLAI is responsible for acquiring and preserving the following resources:

- All textual and nontextual materials published inside the country including books, periodicals, pamphlets, newsletters, posters, maps, audio and video tapes and discs, electronic and digital documents, etc., through National Deposit Act or purchase.

- Resources published outside the country in the fields of Iranian and Islamic studies in non-Persian languages especially English and Arabic, as well as all those published in Persian.

- Authentic and reliable reference and nonreference materials in various fields in non-Persian languages, especially English and Arabic.

\section{WHO THE NLAI SERVES}

The NLAI offers services to clients, libraries, and publishers. The main services provided by the NLAI consist of the following:

1. information services (detailed below)

2. services to other libraries, such as the provision of International Standard for Iranian Libraries (ISIL)

3. services to publishers including Cataloguing in Publication (CIP) Service for books and assigning International Standard Serial Number (ISSN) to periodicals

Among the types of information services provided by the NLAI is reference service through which librarians assist clients doing scientific searches and seeking new information on different subjects. Reference services of the NLAI are presented in two models: traditional reference and digital reference.

\section{TRADITIONAL REFERENCE SERVICE}

Traditional reference service is only open to user members of the NLAI. The NLAI Reading Halls are where traditional reference service is provided. There are four Reading Halls, each named for a prominent Iranian scholar or artist. In each hall there is a reference desk, staffed by a reference librarian who has a master's degree in library and information science.

\section{Ibn Nadim Hall (References and Bibliographies)}

The collection here includes general reference books such as encyclopedias, dictionaries, biographies, bibliographies, abstracts, and thematic tables and lists. It also contains an extensive collection of reference books in the field of library and information science.

\section{Al-Razi Hall (Science and Technology)}

This collection is rich in mathematics, astronomy, physics, chemistry, biology, geology, paleontology, computer science, engineering, medicine, and agriculture. Razi is the busiest hall in the NLAI because of the availability of the latest reference sources on science and technology.

\section{Ibn Sina Hall (Humanities and Social Sciences)}

This reading hall is dedicated to books in the subjects of philosophy, religion, psychology, history, geography, and literature. Ibn Sina Hall is the most spacious hall of the NLAI. Its collection of reference resources in English is unique in the country.

\section{Sohrevardi Hall (Social Science and Art)}

This hall is dedicated to books about social and political science, economics, law, education, arts, and music.

\section{VIRTUAL REFERENCE SERVICE}

The NLAI has offered Virtual Reference service via email since August 2005 and pioneered virtual reference services in Iran. The service is provided via a web form located on the official website of the NLAI (www.NLAI.ir) through the "Ask Us" link. Users can choose who answers their questions in the first field of the web form: either an archive expert or a reference librarian (see appendix A for the web form). In the research discussed here, the virtual reference questions only include questions directed to the reference librarians. At time of writing this paper virtual reference service of the NLAI is staffed by two reference librarians with a master's degree in library and information science. Both members and nonmembers of the NLAI are allowed to use virtual reference service.

\section{MEMBERSHIP CONDITIONS OF THE NLAI}

\section{General Membership:}

Academic qualification at least at a BA/BS level or Level 1 of Seminary Studies;

Note 1: The following applicants are excepted from the above condition:

1-1 High School students ranked 1 to 3 in International Olympiads;

1-2 Inventors and discoverers holding patents;

1-3 Undergraduate students of Library and Information Science of year 2 and higher;

Note 2: University or seminary students must submit a recommendation letter from their academic or seminary institutions with their subject of research specified. This will enable 


\section{FEATURE}

them to use the NLAI's facilities for a maximum period of one month.

1-4 Researchers and authors with at least two published articles in scholarly journals or one monograph (written or translated);

\section{Permanent Membership}

Academics with full professorship receive permanent membership.

\section{Special Membership}

Members of the Iranian academies of sciences, arts, literature, as well as distinguished scholars are admitted as Special Members.

(For additional information on NLAI membership, see http://old.nlai.ir/Default.aspx?tabid=440)

\section{LITERATURE REVIEW}

Very little literature has been published regarding analysis of both traditional and virtual reference queries. A comprehensive literature review was conducted with emphasis on researches from 1984 to the present with particular focus on studies that discussed content analysis of queries of traditional reference and also variety of digital reference models including web form, email, and chat. In 1984 Calabretta and Ross examined types of questions asked in a health sciences library in 1982-83. Thirty two percent of queries were directional questions, while 68 percent were reference queries (card catalog, computer search request, instruction, ready reference, detailed reference, ILL, or photocopying request). ${ }^{1}$ In 1987, Landworth, Wilson, and Dorsch examined types of questions asked at a medical school branch library. They found out that only 42 percent of the clients were library members; 18 percent of them were university students of other universities and 11 percent were society members using the library for finding answers to their questions about personal health. They also analyzed all reference questions in terms of types of questions asked and found that 35 percent of questions were directional, 28 percent were for publication data, 18 percent were subject searches (either manual or computer), 6 percent were general reference, 5 percent were biographical or directory, 5 percent were in-house instruction, 2 percent were for verification, and 1 percent for compiling bibliographies. ${ }^{2}$

In 1994, Hedayat evaluated reference questions asked in the faculty libraries of Shahid Chamran University in Ahvaz (in southwestern Iran) in 1993-94. She analyzed 607 reference questions asked by students at reference desk. The study indicated that most of the questions were answered in fewer than five minutes. Female students asked questions at two times the rate of the male students. Only 35 reference questions were answered using information resources. Hedayat noted that this was because the assessed libraries lacked skilled reference librarians. ${ }^{3}$

In 1994, Sullivan, Schoppmann, and Redman studied all kinds of reference questions asked at the reference desk of Alfred Taubman Medical Library at the University of Michigan. They found that 33 percent of the questions were directory. Twenty seven percent were of the research type and 18 percent were computer-related (providing clients with assistance or training in using computerized systems including OPAC, databases, compact discs, and the Internet), 13 percent were about searching strategy, and 9 percent of the questions were ready reference. ${ }^{4}$

From 1994 to 2001, there were no major studies regarding the analysis of different types of traditional reference questions.

Warner presented a model for classification of all kinds of reference questions in 2001. He divided reference questions into four levels:

- Level 1-nonresource based questions, that is to say, the questions whose answering does not require any specific resource.

- Level 2-questions answered relying on librarians' skills (skill-based questions).

- Level 3-questions requiring formulation of a searching strategy followed by selection of an appropriate resource (strategy-based questions).

- Level 4-questions that require librarian to research or provide a list of resources on the subject (consultation questions) ${ }^{5}$

All of the studies previously noted analyzed traditional reference questions. Beginning in 2001, papers analyzing digital reference transactions begin to be seen. Diamond and Pease analyzed 450 reference transactions received at California State University Chico in an effort to categorize the types of questions. The study showed that users asked similar questions whether in person or via an email reference service. ${ }^{6}$

In 2002, Ware et al. found that of the 418 questions submitted the majority (39 percent) were instructional, followed by research (32.5 percent), ready reference ( 22 percent), and technical (24 percent). Presumably, because these percentages were more than 100 percent, some questions were classified in more than one category. Interestingly, the authors utilized a "standard" typology to create these categories, referring to the "field-tested Lankes/McClure Reference Question Typology."

In 2002, Kelly surveyed usage and performed a user analysis of real-time digital reference service at Bowling Green State University (BGSU) libraries. He determined eight categories of question types including "Article on" (22 percent) in which users asked for articles on a particular topic; "Patron record" (6 percent) covering questions about renewing books; "BGSU info" (4 percent) regarding information about campus events; "Known items" (12 percent) were questions related to the university and library holdings; "Referrals" (2 percent) 
included questions best answered in other areas of the main library such as circulation. The category of "other" (49 percent) represented a large set of extremely diverse questions which the author was not able to categorize. Because other librarians or library students investigated on the service, the researcher included a special category called "other librarians" (3 percent). Finally, the "off-campus access" (2 percent) category included questions about accessing proprietary resources from off-campus. ${ }^{8}$

In 2003, Moeller analyzed transcripts from questions submitted to Ohio State University's Main Library Ask-A-Librarian email reference service to see who was asking questions and what types of questions they were asking. Forty-eight percent of questions were submitted by university affiliates. Types of questions were similar to those asked at the reference desk, with patrons not affiliated with the university being most likely to ask in-depth questions. ${ }^{9}$

De Groote analyzed the questions received at the virtual and traditional reference desks of the University of Medical Sciences of Illinois University, Chicago, during one month. The study dealt with 38 email questions, 48 chat questions, 156 phone questions, and 697 face-to face questions. Of the face-to-face questions, 30 percent were directory questions and 55 percent were other types of reference questions. Most of the questions were about magazines holdings (19 percent), books holdings (12 percent), working hours of the library, its location, etc. (9 percent), library services ( 7 percent), methods of searching databases for finding papers ( 7 percent), and technical information and access ( 8 percent). The analysis showed that 28 percent of the questions were answered by librarians making use of their general knowledge about the library (how to use databases, library policy, and library resources inventory). Twenty-two percent of the questions were answered through the library's OPAC, 22 percent of the questions were answered through searching the online databases and electronic resources, 13 percent of the users were referred to other sections of the library to receive answers to their questions, 7 percent of the questions were answered through consultation with another expert, and only 5 percent were answered making use of printed resources. ${ }^{10}$

Houlson, McCready, and Pfahl analyzed 631 chat reference transcripts from the University of Minnesota Libraries collected from January 2003 to May 2004. Specifically, the patrons' statuses, the length of sessions, the type of chat transactions, and the types of questions asked were examined. The findings determined that though a majority of patrons seeking assistance from the chat reference service were undergraduates (41 percent), graduate students used the service a surprising amount (28 percent). Overwhelmingly, most students needed assistance finding specific items or wanted to know how to locate a resource. However, 17 percent of the undergraduates using this service were seeking in-depth reference assistance. The analysis has allowed the library to transform its chat reference services (including staffing and training) and also informed decisions about overall library services, websites, and collections. ${ }^{11}$
Henry and Neville in 2008 assessed two reference question classification systems including William Katz's categorization and Warner classification scheme using data from a small academic library. Results indicated that a skill/strategybased approach, rather than a system based on resources used or time allocated per question, led to more consistent classification and provided a more accurate reflection of today's reference desk activity and because the library's resources included so many electronic and technological items, Warner's system appeared more applicable. ${ }^{12}$

Meserve et al. dealt with the feasibility of classification of reference questions in compliance with the model proposed by Warner in the reference section of Dr. Martin Luther King, Jr. (MLK) library located in California. They found out that this model was appropriate for classification of reference questions in their library and could be generalized to all kinds of libraries. ${ }^{13}$

Morais and Sampson assessed the use of the chat reference service by students, faculty, and alumni at the Georgetown University Law Library during 2008. The transcripts yielded 2,303 reference queries, 64 percent of which were ready reference oriented or instructional in nature. Twenty-five percent were known item-type queries, and the final 6 percent and 5 percent were, respectively, policy and technical queries. The results indicated that professional librarians familiar with Georgetown's collections should staff the service. ${ }^{14}$

In 2011, Mohammadi analyzed the types of questions asked at virtual reference desk of the NLAI. Also she surveyed the extent to which users of virtual reference were satisfied with the service. The population study was 317 web forms selected via systematic random sampling according to Morgan's table. Findings showed that most of the users of the service were women ( 52.05 percent) and 88.96 percent of them were university-educated. Research questions were the most commonly asked question type (42.14 percent). Delay in receiving responses (33.33 percent) was the main factor of dissatisfaction. Nearly 70 percent of the users had used the service more than once. The most important factor influencing user satisfaction was the completeness of the responses (71.6 percent). Users expected to use the virtual reference services via email (50.20 percent) and then chat (38.34 percent). ${ }^{15}$

\section{RESEARCH QUESTIONS}

This study seeks to answer the following questions:

1. What are the similarities and differences in the demographic specifications of traditional and virtual reference users (from the views of gender, educational degree, and educational group)?

2. What are types and subjects of the reference questions at the NLAI?

3. Is there any significant relationship between educational level and use of virtual and traditional reference services? 


\section{FEATURE}

4. Is there any significant relationship between educational level and types of reference?

5. Is there any significant relationship between types of questions and educational degrees of traditional and virtual reference users?

6. To what extent do traditional reference clients use virtual reference services of the NLAI?

7. How many users of digital reference are members of the NLAI?

\section{METHOD}

Reference services are presented in both traditional and virtual models at the NLAI. Traditional reference services are provided face-to-face or via telephone by reference librarians. Virtual reference service is provided via email using a web form. All questions received within one month from December 2, 2010, up to January 2, 2011, were recorded to gather the data for this study. Within this time interval, 178 web forms were received which included 258 questions (users can ask more than one question in a web form) and 354 reference questions were asked at traditional reference desks. Web form fields include name, email address, educational level, educational field, and question so that librarians understand the user's information need as clearly as possible (see the web form included in appendix A).

Each reference question and answer were recorded with the following parameters: demographic information of user (gender, educational degree, educational field, educational group), question, explanation of answer given, type of question, subject of question, the extent to which clients of traditional reference services ever used digital reference service, and finally whether the virtual reference user is a member of the NLAI.

Demographic information of those who asked virtual reference questions was obtained from the web form. For face-to-face encounters, reference librarians filled all parameters on the form except for type, subject of question, and educational group of client.

Every question and answer was considered as one record, web forms were coded, and then the data was analyzed using SPSS software.

As previously noted in the literature review there are existing categorizations for determining types of reference questions. Some researchers categorized reference questions without using a model but there are at least two models for classification of reference queries: the Katz model and the Warner model. The Warner model is based on skills or strategies required to address questions rather than on length of time taken or resources used. ${ }^{16}$ Katz's categorization is mainly based on the response given to a user. Since the researchers in this study had recorded all the responses to reference questions, Katz's categorization was used for determining types of traditional and virtual reference questions.

Katz divided reference questions into four categories: directional, ready reference, special searching, and research questions. Directional questions are self-evident: where is the library catalog? Do you have a photocopy machine? Ready reference usually refers to those questions that may require the use of a standard reference work such as a handbook, almanac, dictionary, or directory. Specific search questions may involve demonstrating how to use book catalogues and electronic databases to find information on a well-defined research question such as opposing viewpoints on current issues. This category of question may actually evolve into the fourth category, in-depth research questions. The research question often requires the services of a subject specialist or exploring resources that are not common or readily accessed. ${ }^{17}$ Dewey decimal classification was used for determining subject area of the reference questions. Considering the diversity of the users' fields of study, all educational fields were divided into five groups including human sciences, medical sciences, basic sciences, technical and engineering sciences, and art. Question types and subjects were determined by researchers and then the different views were discussed in a joint session so as to reach agreement.

\section{FINDINGS}

A total of 617 questions were received at traditional and virtual reference desks of the NLAI, of which 58.83 percent were traditional reference questions and 41.17 percent were virtual reference queries.

The most frequently asked reference questions by type were ready reference questions with 33.55 percent while the least frequently asked queries were research questions with 17.34 percent (see figure 1).

\section{Demographic Information of Traditional and Virtual Reference Users}

As figure 2 indicates 66.6 percent of the users met their information needs via traditional reference desks. The females (65.53 percent) mostly used traditional reference service but more males ( 54.55 percent) used virtual reference service.

Not surprisingly use of the traditional reference desks was higher among those users who hold master's degrees compared to their use of the virtual reference service. Meanwhile, the users who hold high school diplomas and associate's degrees (owing to their not being qualified for the library membership) more commonly used virtual reference service. Virtual service is the most accessible service of the NLAI to nonmembers who are not allowed to enter the library and use its services and thus may not ask questions at the traditional reference desks (see figure 3).

As noted in figure 4 , the greatest number of users of both traditional and virtual reference services were in the humanities. The basic sciences had the lowest rate for traditional reference services and the basic and medical sciences groups had the lowest rate for virtual reference. Having a better understanding of virtual users, we will be able to identify needs for 
digital resources and help the NLAI choose scientific databases to subscribe to and digitize the resources which best meet users' information needs. It is noted that up to now the NLAI does not subscribe to any international scientific databases. freedom angle of 9 and the $\alpha$ of 0.05 , there was no significant relationship between educational level and types of questions. In other words, holders of all educational degrees made same use of both traditional and virtual reference services. This result is contrary to the expectations of the researchers. Because the

\section{Type and Subject of Reference Questions}

According to the analysis of the questions asked at traditional reference desks as well as through virtual reference, the most and the least question common types of traditional reference questions were ready reference ( 42.42 percent) and research questions (6.89 percent) respectively; and those of virtual reference were research (32.28 percent) and directory (20.08 percent) questions (see figure 5).

With nearly 80 percent of queries of traditional reference being ready reference questions (42.66 percent) and directory (37.29 percent) the NLAI clients are clearly not using traditional reference services to meet their research needs (6.78 percent). Since research questions generally require more extensive interviews, it would have been expected that clients with these questions would pose them to librarians at the traditional reference desks. It seems that the library has not properly marketed reference services and informed users on the capabilities of reference librarians. As trained specialist librarians are necessary for answering research questions at the reference section, reference librarians should actively participate in the training information literacy skills workshops held inside and outside the NLAI. In addition, cooperation of subject specialists with reference librarians is needed to further encourage clients to make use of reference services.

As table 1 shows, the most frequently asked questions by clients of traditional reference desks were classified in computer science, information, general works (000) with 21.05 percent and the least frequently asked questions were classified in philosophy and psychology (100) with 1.32 percent. Interestingly the results were similar for users of virtual reference.

The chi squared test calculated (78.1) was significant at the freedom angle of 3 and the $\alpha$ of 0.05 , indicating a significant relationship between educational level and kinds of services used (traditional and virtual). Holders of doctorates and master's degrees made greater use of both traditional and virtual reference services (see table 2).

Considering the fact that calculated chi squared test (19.5) was not significant at the

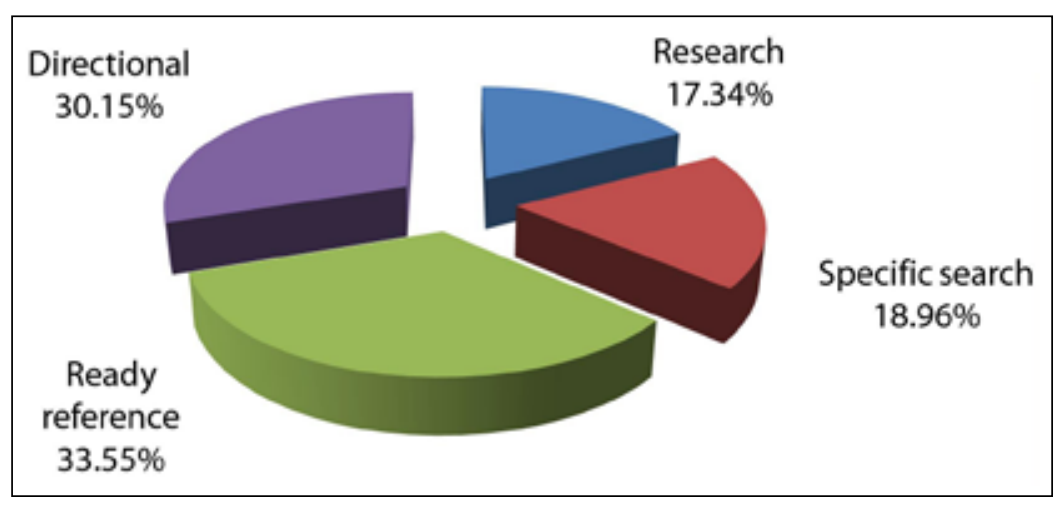

Figure 1. Traditional and Virtual Reference Questions by Type

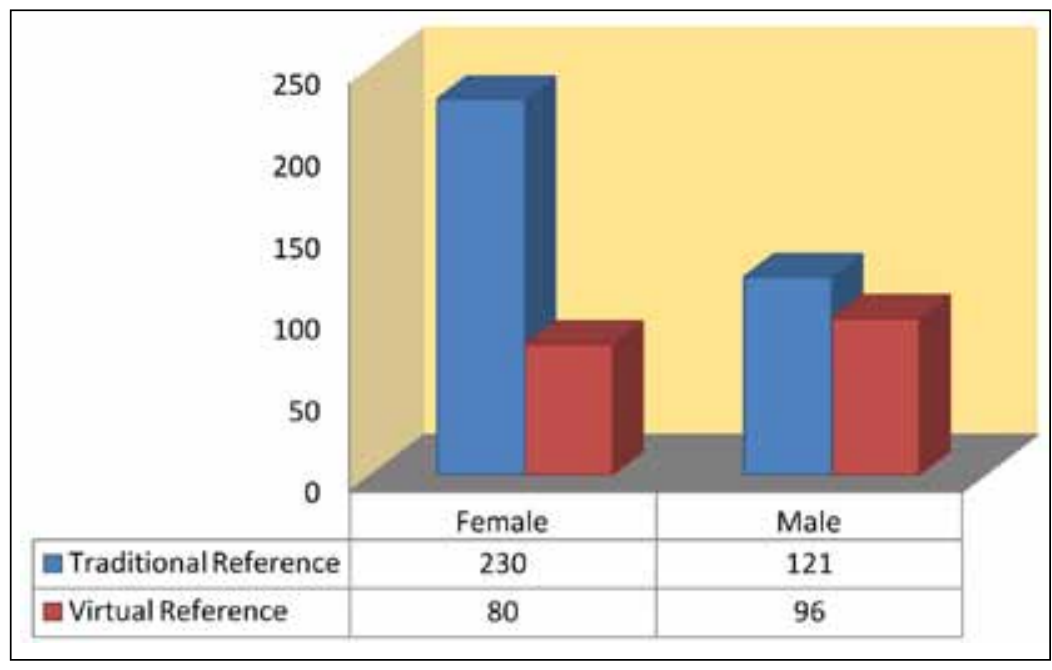

Figure 2. Traditional and Virtual Reference Users by Gender

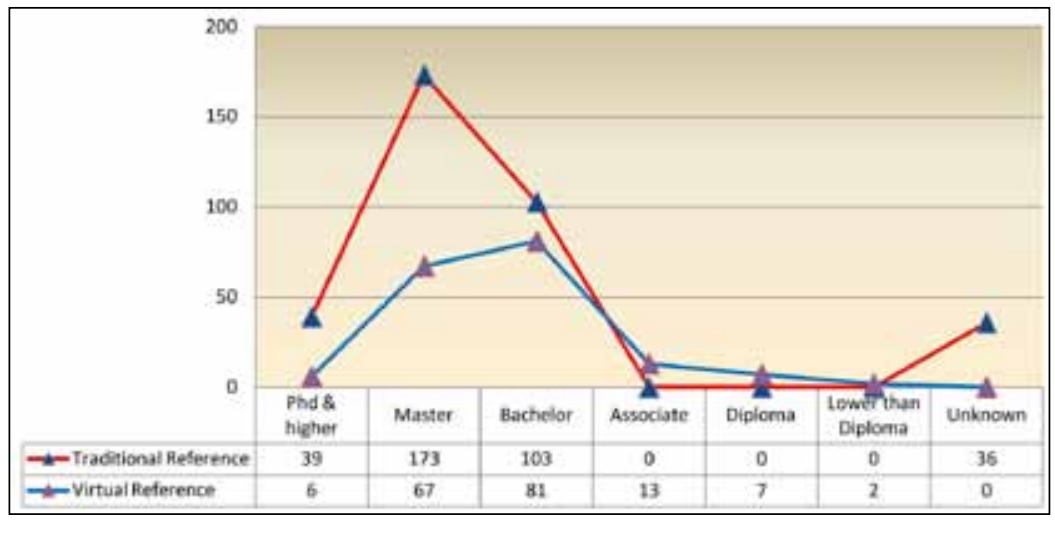

Figure 3. Traditional and Virtual Reference Users by Educational Level 


\section{FEATURE}

NLAI has very rich information resources it was expected that members with doctorate and master's degrees would mostly

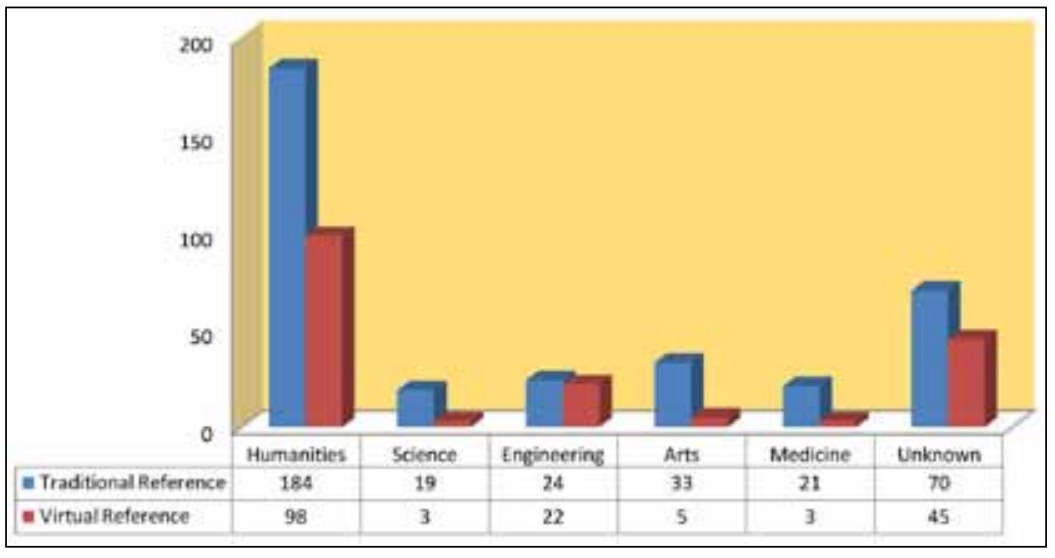

Figure 4. Traditional and Virtual Reference Users by Educational Group

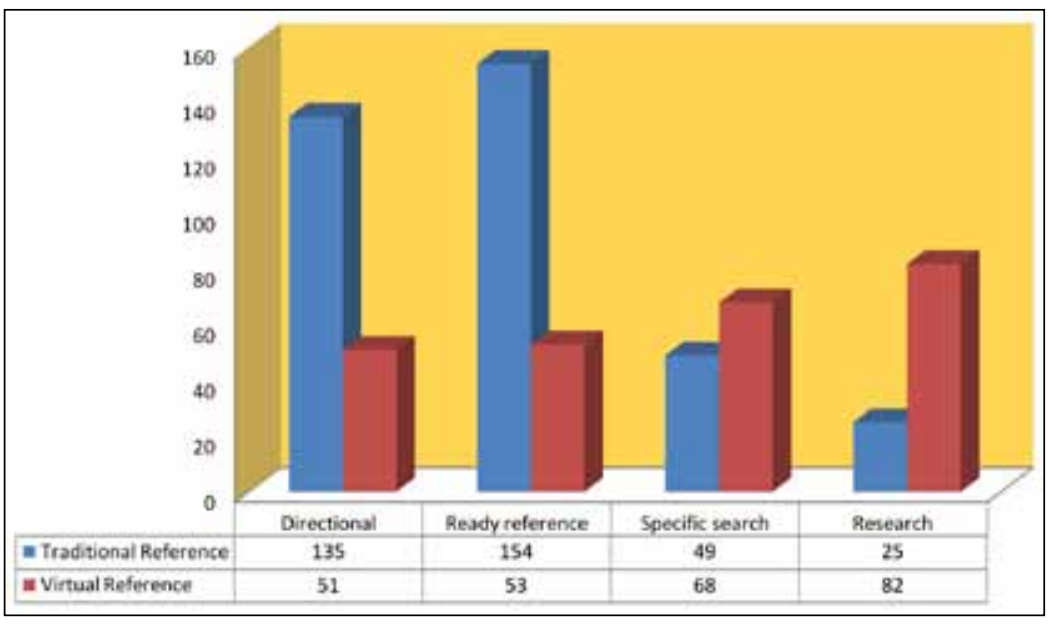

Figure 5. Traditional and Virtual Reference by Question Type ask questions through using reference services for performing their dissertations and projects (see table 3).

Reference librarians asked the clients whether they had ever used virtual reference service or not. The librarians explained the virtual reference service to those clients who were unfamiliar with to encourage them to use the virtual service in the future. The results of the research showed that only 7.98 percent of clients of traditional reference desk used virtual reference service. This may indicate that a few numbers of them knew that virtual reference service was provided by the library (see table 4).

Only 10.23 percent $(n=18)$ of users of the NLAI virtual reference were members of the NLAI. The findings of the research indicated that, so far, about 8 percent of the clients used virtual reference services. It is, therefore, suggested that the NLAI hold workshops for presentation of library services especially virtual reference services, inform members of service options via email, prepare electronic brochures and send them to all members periodically to encourage all members, especially researchers, to use such services. Because the most frequently asked questions in virtual reference were of the research type, marketing of reference services will substantially pave the way for increased productivity and saving researchers' time (see table 5).

\section{CONCLUSION}

Findings of the research showed that although virtual reference service was used less than traditional reference services, it was more commonly

Table 1. Traditional and Virtual Reference Questions by Subject based on DDC

\begin{tabular}{|c|c|c|c|c|c|}
\hline $\begin{array}{l}\text { Dewey } \\
\text { Classification }\end{array}$ & $\begin{array}{l}\text { Traditional } \\
\text { Reference }\end{array}$ & Percentage & Virtual Reference & Percentage & Total Percentage \\
\hline 000 & 48 & 11.29 & 82 & 19.29 & 30.58 \\
\hline 100 & 3 & 0.71 & 2 & 0.47 & 1.18 \\
\hline 200 & 18 & 4.24 & 24 & 5.65 & 9.88 \\
\hline 300 & 27 & 6.35 & 27 & 6.35 & 12.71 \\
\hline 400 & 20 & 4.71 & 3 & 0.71 & 5.41 \\
\hline 500 & 17 & 4 & 9 & 2.12 & 6.12 \\
\hline 600 & 36 & 8.47 & 15 & 3.53 & 12 \\
\hline 700 & 9 & 2.12 & 5 & 1.18 & 3.29 \\
\hline 800 & 21 & 4.94 & 18 & 4.24 & 9.18 \\
\hline 900 & 23 & 5.41 & 18 & 4.24 & 9.65 \\
\hline Total & 222 & 52.24 & 203 & 47.76 & 100 \\
\hline
\end{tabular}


used for research purposes. This indicates that researchers and academic students value virtual reference service. Additionally, this suggests that it will be important for other libraries in Iran to look at offering virtual services. In addition, there is a need to have reference librarians with expertise in the areas where questions are most often asked.

Females used traditional reference service more than the males. It is interesting to note that 55.1 percent of the members of the NLAI are females. Librarians staffing the traditional reference desk are all female except for one. Usually in IranianIslamic cultural behavior the males prefer to ask help of the male librarians and females of female librarians. This may be one of the reasons why female clients used traditional reference service more frequently. In virtual reference service the gender of the librarian is unknown to the user and so virtual reference service may be a good way to expand the library's services despite the cultural differences noted above.

The findings indicated that the most questions clustered in computer science, information, and general works (000) but that users studying humanities asked more reference questions.

Table 2. The Chi Squared Test for Determination of Relationship between Educational Degree and Use of Reference Services

\begin{tabular}{lcc}
\hline $\begin{array}{l}\text { Education } \\
\text { Degree }\end{array}$ & $\begin{array}{c}\text { Traditional } \\
\text { Reference }\end{array}$ & Virtual Reference \\
\hline PhD & 39 & 7 \\
\hline Master's degree & 173 & 98 \\
Bachelor's degree & 103 & 110 \\
\hline $\begin{array}{l}\text { Associate degree } \\
\text { and lower }\end{array}$ & 0 & 40 \\
Total & 315 & 255 \\
$\mathrm{p} \leq 0.05$ & $\mathrm{Df}=3$ & $\mathrm{X} 2=78.1$ \\
\hline
\end{tabular}

An investigation was done that showed that from the humanities group, the field of Library and Information Science (13.96 percent) was on the first rank. This seems to indicate that librarians used these kinds of reference services more than users of other fields because they are more familiar with these information services in libraries. Again, it seems that the NLAI should seriously market these services so that users of other fields of sciences especially researchers make effective use of virtual reference service.

Humanities researchers were the largest group using the reference services of the NLAI. This is not surprising because, according to recent report declared by Ministry of Science, Research, and Technology, 44 percent of graduates in Iran studied in the humanities, which ranked first among educational groups. ${ }^{18}$ Holders of doctorates and master's degrees made greater use of traditional reference services. It is expected that these users refer to reference desk mostly to acquire needed information for academic purposes and in fact ask their research questions. On the other hand a large proportion of traditional reference queries were ready reference and directory ones. This means that clients are not effectively using traditional reference service to meet their research needs. There could also be an investigation into the reasons. Why they don't they refer to reference librarians for this purpose? Do they think that they know more than reference librarians about their fields? Do they know exactly what the tasks of reference librarians are? Do they think that they know search strategies better than reference librarians? Are they exactly familiar with capabilities of reference librarians? All these should be surveyed in other studies.

There could be various reasons for the tangible difference in the number of research questions raised in traditional and virtual reference. Future research could focus on the differences and quality of answers provided in virtual and traditional reference services.

Table 3. Relationship between Educational Levels and Types of Traditional and Virtual Reference Questions

\begin{tabular}{|c|c|c|c|c|c|c|}
\hline Types of Questions & PhD & \multicolumn{2}{|c|}{ Master's Degree } & \multicolumn{2}{|c|}{ Bachelor's Degree } & $\begin{array}{l}\text { ate's Degree } \\
\text { d lower }\end{array}$ \\
\hline Directional & 7 & \multicolumn{2}{|c|}{67} & \multicolumn{2}{|c|}{71} & 12 \\
\hline Ready reference & 20 & \multicolumn{2}{|c|}{109} & \multicolumn{2}{|c|}{61} & 6 \\
\hline Specific search & 13 & \multicolumn{2}{|c|}{46} & \multicolumn{2}{|c|}{45} & 8 \\
\hline Research & 6 & \multicolumn{2}{|c|}{49} & \multicolumn{2}{|c|}{36} & 14 \\
\hline \multirow[t]{2}{*}{ Total } & 46 & \multicolumn{2}{|c|}{271} & \multicolumn{2}{|c|}{213} & \multirow{2}{*}{$\begin{array}{c}40 \\
x 2=19.5\end{array}$} \\
\hline & $\mathrm{p} \leq 0.05$ & \multicolumn{2}{|c|}{67} & \multicolumn{2}{|c|}{$\mathrm{Df}=9$} & \\
\hline \multicolumn{3}{|c|}{$\begin{array}{l}\text { Table 4. Use of the NLAI Virtual Reference Service by Clients of } \\
\text { Traditional Reference }\end{array}$} & \multicolumn{4}{|c|}{$\begin{array}{l}\text { Table } 5 . \text { How many users of virtual reference were members of } \\
\text { the NLAI? }\end{array}$} \\
\hline The Use of Virtual Reference & Frequency & Percentage & \multicolumn{2}{|c|}{ Membership status } & Frequency & Percentage \\
\hline No & 323 & 92.02 & \multicolumn{2}{|c|}{ Member } & 18 & 10.23 \\
\hline Yes & 28 & 7.98 & \multicolumn{2}{|c|}{ Nonmember } & 158 & 89.77 \\
\hline Total & 351 & 100 & \multicolumn{2}{|l|}{ Total } & 176 & 100 \\
\hline
\end{tabular}




\section{FEATURE}

\section{References}

1. N. Calabretta and R. Ross, "Analysis of Reference Transactions Using Packaged Computer Programs," Medical Reference Services Quarterly 3 (Fall 1984): 23-47.

2. T. K. Landworth, M. L. Wilson, and J. L. Dorsch, "Reference Activity and the External User: Confluence of Community Needs at a Medical School Branch Library," Bulletin of the Medical Library Association 76 (1998): 205-12.

3. Marzieh Hedayat, "Evalution of Reference Queries in College Libraries of Ahvaz Shahid Chamran University in 1993-1994" (MS diss., Tehran University, 1994).

4. W. Sullivan, L. A Schoppmann, and P. M. Redman, "Analysis of the Use of Reference Services in an Academic Health Sciences Library," Medical Reference Services Quarterly 13 (1994): 35-55.

5. D. G. Warner, "A New Classification for Reference Statistics," Reference \& User Services Quarterly 41 (2001): 51-53.

6. W. Diamond, B. G. Pease, "Digital Reference: A Case Study of Question Types in an Academic Library," Reference Services Review 29 (2001): 210-19.

7. S. Ware et al., "Ask a Penn State Librarian, Live: Virtual Reference Service at Penn State," Reference Librarian 79/80 (2002-3): 281-95

8. M. Broughton Kelly, "Usage and User Analysis of a Real-Time Digital Reference Services," Reference Librarian 38 (2002): 183-200.

9. Sherry Engle Moeller, "Ask-A-Librarian: An analysis of an E-mail Reference Service at a Large Academic Library," Internet Reference Services Quarterly 8 (2003): 47-61, accessed November 10, 2011 , www.mendeley.com/research/askalibrarian-an-analysis-of- an-email-reference-service-at-a-large-academic-library.

10. Sandra L. De Groote, "Questions Asked at the Virtual and Physical Health Science Reference Desk: How Do They Compare and What Do They Tell Us?," Medical Reference Service Quarterly 24 (2005), accessed November 10, 2011, www.mendeley.com/ research/questions-asked-virtual-physical-health-sciences-reference-desk-compare-tell.

11. V. Houlson, K. McCready, and C. S. Phfal, "A Window into Our Patron's Needs: Analyzing Data from Chat Transcripts," Internet Reference Services Quarterly 11 (2006): 19-39.

12. D. B. Henry and T. M. Neville, "Testing Classification Systems for Reference Questions," Reference \& User Services Quarterly 47 (2008): 364-73.

13. Harry C. Meserve et al., "Developing a Model for Reference Research Statistics-Applying the 'Warner Model' of Reference Question Classification to Streamline Research Services," Reference E User Services Quarterly 48 (2009): 247-58.

14. Morais Yasmin and Sampson Sara, "A Content Analysis of Chat Transcripts in the Georgetown Law Library," ,29: (2010): 165-78.

15. Farnaz Mohammadi, "Qualitative Evaluation of Virtual Reference Service of National Archive and Library of Iran and Suggesting an Appropriate Pattern" (MS diss., Islamic Azad University, North Tehran Branch, 2011).

16. Warner, "A New Classification for Reference Statistics," 53.

17. William Katz, Introduction to Reference Work, 8th ed. (Boston: McGraw-Hill, 2002), 16-18.

18. Rajanews, "Increasing Number of Students of Humanities in Recent 10 Years," accessed November 10, 2011, http://rajanews. com/Detail.asp?id=128484.

\section{APPENDIX A. VIRTUAL REFERENCE WEB FORM USED AT THE NLAI}

\begin{tabular}{|c|c|c|}
\hline Question From: & Librarian & + \\
\hline \multicolumn{2}{|l|}{ Name: } & \\
\hline \multicolumn{2}{|l|}{ *E-mail: } & \\
\hline \multicolumn{2}{|l|}{ ID Card: } & \\
\hline Education Level: & - & $\nabla$ \\
\hline \multicolumn{2}{|l|}{ Educational Field: } & \\
\hline \multicolumn{2}{|l|}{ City: } & \\
\hline Country:: & Iran $\quad$ & \\
\hline \multirow{4}{*}{$\begin{array}{l}\text { Language(s) of Requested } \\
\text { Resources: }\end{array}$} & \multicolumn{2}{|l|}{$\square$ Persian } \\
\hline & \multicolumn{2}{|l|}{$\square$ English } \\
\hline & \multicolumn{2}{|l|}{ Arabic } \\
\hline & \multicolumn{2}{|c|}{ Other Languages } \\
\hline
\end{tabular}

\begin{tabular}{|c|c|}
\hline \multirow[t]{5}{*}{ Requested Resource Types: } & $\square$ Book \\
\hline & $\square$ Article \\
\hline & $\square$ Thesis \\
\hline & ل Non-Book Resources \\
\hline & $\square$ Internet Resources \\
\hline \multirow{5}{*}{$\begin{array}{l}\text { Other Resources which } \\
\text { you referred but you } \\
\text { didn't get the answer: }\end{array}$} & $\square$ The NLAI Website \\
\hline & $\square$ OPAC \\
\hline & Other Libraries \\
\hline & $\square$ Internet \\
\hline & $\square$ FAQ \\
\hline
\end{tabular}

